ma, el público de París se inclina ante esta fila de cadáveres. románticos como ante spécimens curiosos de museo, cortados todos los hilos, aún de la más lejana conexión.-M A R T A VE R G A R A.

\title{
Orientaciones del arquitecto
}

- 1 N 1928, en el Castillo de La Sarraz, Suiza, celebróse un Congreso Internacional de Arquitectos, en el que fueron echadas las bases de una agrupación internacional y se estableció un programa de acción común. La asamblea publicó un manifiesto que exponía el papel del arquitecto en la sociedad y los diversos problemas que le conciernen. Veinticuatro arquitectos firmaron la siguiente declaración:

Los arquitectos sucritos, representantes de grupos nacionales de arquitectos modernos, afirman su unidad de criterio sobre las concepciones fundamentales de la Arquitectura y sobre sus deberes profesionales hacia la sociedad. Insisten particularmente en el hecho de que econstruir s es una actividad elemental del hombre, actividad que está íntimamente ligada a la evolución y al desarrollo de la vida humana. La tarea de los arquitectos consiste en ponerse de acuı rdo con la orientación de su época y sus obras deben expresar el espíritu de su tiempo. Rehusan, por consiguiente, emplear en su método de trabajo los principios que han podido animar a las sociedades pasadas, y afirman, por lo contrario, la necesidad de una concepción nueva de la Arquitectura, que satisfaga las exigencias espirituales, intelectuales y materiales de la vida presente. Conscientes de las transformaciones profundas aportadas a la estructura social por el maquinismo, reconocen que la transformación del orden y de la vida social entraña fatalmente la correspondiente transformación del fenómeno arquitectural.

Extraña que los arquitectos, cuyo papel es construir, pretendan explicarnos por medio del lenguaje las razones que determinan su obra, y más aún nos ha de extrañar, si sus declaraciones, como las trascritas, salen de la zona artística y abarcan campos que hasta ahora han permanecido indiferentes para ellos. Porque, aunque no es la primera vez que esto sucede, ya que muchos arquitectos han expuesto en diversa forma las razones de su obra o el concepto que tenían de su profesión y del ejercicio de ella, es la primera vez, en cambio, que el arquitecto abandona su actitud meramente artística, meramente creadora, y se traslada al campo de las realidades 
sociales. Quizá si el precursor de estos modernos arquitectos sea Viollet le Duc, que en 1863, desde su cátedra de la Escuela de Bellas Artes de París, se pronunció de manera oficial sobre la intervención-desacertada siempre-del Estado en la enseñanza de las Bellas Artes, actitud que costó al maestro su cátedra y la amargura de verse rechazado por sus propios alumnos.

Sea como sea, lo cieito es que nos encontramos ante una actitud nueva de los arquitectos y que esta actitud traerá más de una sorpresa y muchos beneficios. ¿Qué trascendencia tiene esta actitud? En primer lugar, si construir es una actividad elemental del hombre y si el que construye, o sea el arquitecto, rechaza las normas pasadas y afirma su libertad de criterio y de acción, desligándose al mismo tiempo de los lazos que antiguamente lo unían con los poderes públicos y con la riqueza, se realiza un asombroso fenómeno de independencia que, como todos los fenómenos de independencia, traerá a la colectividad un ejemplo digno de imitarse, ya que tan raros son. En segundo lugar, esta actitud va a aumentar matemáticamente el bienestar de los hombres, ya que el arquitecto, constructor de su vivienda, desligado de intereses personales, no se preocupará sino de hacerla en la mejor forma posible, contemplando, antes que nada, los deseos del que la habitará. Hasta hace poco tiempo y en todo el mundo, el arquitecto, como otros artistas, fué sólo un servidor humilde de la riqueza, un ejecutor, sin criterio, de órdenes ajenas. Su labor se reducía a construir lo que se le mandara, sin que pudiera exponer razón u opinión alguna que no fuera de índole estética pura. La enseñanza de la Arquitectura, por otra parte, se ha realizado siempre en abstracto, en líneas, podríamos decir, excluyendo el sentido social que la Arquitectura, como otras artes o como otras ciencias, debe poseer para ser completa. Esa anterior falta de criterio personal sobre las necesidades y deseos de la sociedad y esa enseñanza que excluía la parte social de la Arquitectura, trajeron como consecuencia el fabuloso amontonamiento humano de las ciudades europeas y del mundo, en que las construcciones fueron realizadas sin tener en cuenta otra cosa que los intereses personales del que hacía edificar, olvidando los intereses generales de la población, los intereses morales, higiénicos, de bienestar, a que todos tienen derecho.

Es decir que el arquitecto desea, no diremos recuperar, sino cobrar el papel técnico que como a creador le corresponde. ¿Quién debe dictaminar sobre las formas y condiciones en que se construirá una casa, una villa, un barrio o una ciudad? 
El que la construye, el arquitecto, así como es el higienista quien debe establecer los reglamentos y las obras de salubridad y el médico las de hospitalización y atención médica. Se realizaría o se realiza de este modo el desplazamiento del Estado en aquellas actividades técnicas que no son de su incumbencia y que siempre, aun en los países adelantados, se prestan a manejos y a perturbaciones provocadas por los intereses particulares. He ahí el valor de esa actitud. El Estado debe tomar una forma simplemente administrativa, amenguar su monstruoso crecimiento que pretende absorber todas las manifestaciones espirituales y materiales de la vida del hombre y ceder el puesto a los creadores, sabios o artistas, en aquello que les corresponde como a tales.

El arquitecto, planteado así su papel tiene ante sí una gran obra que realizar. Ya en Francia y otros países europeos le han sido confiadas las construcciones de grandes grupos de casas para burgueses y para obreros, construcciones que verificará sin tomar en cuenta otra cosa que no sea el interés, de las personas que en esas casas van a vivir: aire, luz, agua, comodidad, amplitud. Los nuevos materıales de construcción, especialmente el cemento, como dice André Lurçat, al revolucionar el arte de construir, permiten perfeccionar el plan de las casas, edificar casas aireadas e iluminadas profusamente, sanas y confortables. Todos los nuevos aportes de la industria permiten una mejor manera de vivir, encaminándonos hacia una nueva moral.

De la posibilidad de crear formas nuevas, resulta la aparición de una nueva concepción plástica.

Y no solamente plástica, sino también social, que es la parte más interesante de este movimiento de los arquitectos jóvenes de Europa.

Las nuevas formas de vida, el crecimiento del maquinismo, el enorme desarrollo de las ciudades, en que se concentran las fábricas y las industrias, hacen necesaria la aparición de nuevas formas arquitectónicas y estas formas deben corresponder a las necesidades y a los deseos de las masas que mueven esas ciudades, esas industrias, esas fábricas. El valor hombre debe ser contemplado como el principal valor de las sociedades y dársele las comodidades a que tiene derecho.

Los arquitectos jóvenes llegan incluso a preconizar la desaparición de la propiedad privada y el advenimiento de la propiedad colectiva. $Y$ es que lanzados por la pendiente de la 
independencia y acercándose a un sentido humano amplísimo, su camino ya no se detendrá sino hasta llegar a límites insospechados y sorprendentes.-M A N U L R O J A S.

\section{Glosa del individualismo español}

7 IENTRAS avanzaba el enemigo devastando ciudades, la energía indomable de Clemenceau era la voz de aliento para la Francia invadida. Todos los espíritus se hallaban fatigados y perdidas todas las esperanzas cuando la suerte de la guerra se puso en manos del estadista genial. Al ser convertido éste en director, en Patriarca de los pueblos aliados, llegó al Parlamento para decir con su natural y terrible crudeza: $A$ mi edad no he venido al Gooierno para perder el tiempo; he venido para hacer la guerra. Y este fué su estribillo durante largo tiempo. En su voz se cernía un eco de La Marsellesa. Los poilus lo apodaron El Tigre al verlo en los campos de batalla, entre los generales, en medio de la muerte, tranquilo, sólido, firme. Hacía la guerra, hacía la victoria y, más tarde, hizo la paz en la asamblea de las naciones vencedoras.

Pasados los trágicos momentos de peligro, quiso la República investir de la Suprema Magistratura al Padre la Vicioric; pero fracasó su candidatura presidencial y volvió al retiro de su estudio, a continuar sus obras, sin que sus energías desmayaran un solo instante, sin sentir siquiera el desfallecimiento de la ancianidad.

Ninguna otra circunstancia de la política francesa, en los últimos años, contiene una enseñanza más trascendental que esta. La disciplina colectiva, la existencia de sólidos principios determinan la supervivencia de la vida nacional, de las actividades políticas, tras el desaparecimiento de su figura máxima. En tal ambiente, cada cual es el hombre de una hora, de una necesidad, de un deber, sin requerir universalidad de conocimientos ni multiplicidad de actuaciones. Asíse alcanza una cultura cívica suficiente para hacer comprender al estadista cuándo ha pasado su hora e impulsarlo a continuar sus trabajos particulares, sin pretender enseñorearse del poder, mientras presta conformidad a las masas y las enseña a no 